\title{
Gold-Containing Brazing Filler Metals
}

\author{
Arthur M. Tasker \\ International Gold Corporation, New York, N.Y. U.S.A.

\begin{abstract}
Brazing filler metals which contain 37 to 82 percent gold are used for braxing of iron-, nickeland cobalt-base alloys in application in which bigh resistance to oxidation or corrosion is required. Because of theirlow rate of interaction with the base metal, they are ideal for joining thin sections of materials and are commonly used for this purpose. The American Welding Society (AIWS) has designated several standard composition groupings to accommodate different temperature requirements-to permit step-braxing, for example-and brazing processes, including those applicable to vacuum furnaces.

At the recent Braxing and Soldering Conference beld in Pbiladelpbia, from April 24-29th, the AWS and the Gold Institute jointlysponsored a symposium at which the development of several new gold alloys and their comparative performances were discussed.
\end{abstract}

J.G. Richardson, WESGODivision, GTEProducts, chairman of the symposium, summarized a panel discussion held during the session by stating that, despite their relatively high cost, gold alloys continue to be used for brazing because of their high reliability. For critical components, prototypes or low-volume production, it was observed that gold filler metals are often preferted because of their superior liquid flow characteristics compared to other materials.

Because of the high cost of gold, alloy development ptogrammes tend to focus on more economical compositions which do not compromise the performance attainable with standard products.

\section{Space Shuttle Main Engine Assembly}

For the assembly of the Space Shuttle Main Engine it is necessary to braze 1080 tubes of nickel-plated precipitation-hardening stainless steel, A-286, together and to an outer jacket of INCONEL $(\mathrm{R}) 718$; in all, about $6.4 \mathrm{~km}$ of braze joints in a single assembly. The tubes act as the coolant circuit for the nozzle, transporting $120 \mathrm{~kg}$ ofliquid hydrogen per second at an inlet pressure of $46 \mathrm{MPa}$ and an inlet temperature of $-220^{\circ} \mathrm{C}$. The design life of the nozzle is 240 cycles, a total time of 7.5 h under a heating load of $21980 \mathrm{kcal} / \mathrm{s}$.

The objective of the filler metal development programme, reported by A. Brennan and R.D. McKown, Rocketdyne Division of Rockwell International, was to develop two alloys (for first and second-cycle braze operations respectively) which minimized the erosive nature and optimized the strength and durability of goldcopper alloys, the preferred 'base-line' system. By adding nickel and palladium, the strength of the filler metals was increased, base-metal penetration limited, and high-temperature oxidation tesistance maintained. Manganese additions were varied to control melting point. The authors claim that the new alloys have improved gap filling capability and excellent substrate wetting characteristics. Final alloys selected were:

(a) First Braze Cycle

Chemistry: 35 gold $/ 14$ nickel/10 palladium/9.5 manganese/ 31.5 copper (bal.) per cent
Melting Range: $982-1004^{\circ} \mathrm{C}$

Brazing Range: $1038-1052^{\circ} \mathrm{C}$

(b) Second Braze Cycle

Chemistry: 31 gold $/ 10$ nickel $/ 10$ palladium $/ 16$ manganese/ 33 copper (bal.) per cent

Melting Range: $926-949^{\circ} \mathrm{C}$

Brazing Range: $982-996^{\circ} \mathrm{C}$

These alloys met all the requirements for brazing, including operating temperaturescompatible with heat-treatment cyclesfor the base metals. Approximately $10^{5} \mathrm{~m}$ of tubing have been brazed with no thinning of the walls due to erosion. No visible corrosion or corrosion failures were observed in accelerated stress corrosion testing in saline environment, or in exposure to the Florida coast marine environment where the launch site is located. The alloy system is not susceptible to hydrogen embrittlement.

Because of the good ductility of the alloys, theycan be produced in the form of wire, foil ( $0.038 \mathrm{~mm}$ thick $)$ and powder, which permits preplacement of the filler metal in various joint geometries. Figure 1 illustrates a complete sheathing of the interior of the nozzle by the gold alloy foil in order to braze the tubing to the nozzle wall.

It is predicted that after further design refinements have been made to the fitting of components during nozzle assembly, each main engine nozzle will optimally require about $6.2 \mathrm{~kg}$ of gold as filler metal.

\section{Improved Nickel-based Filler Metals}

A need for improvement in the ductility of joints brazed with nickel-based filler metals has led to the development of new alloys containing gold or palladium. Use of standard nickel-chromiumboton-silicon alloys (AWS Series BNi) frequently results in the formation of hard, brittle intermetallic phases which have a deleterious effect on the mechanical properties of brazed joints.

As described by E. Lugscheider and H. Pelster of the Material ScienceDivision, TechnicalUniversity of Aachen, Federal Republic of Germany, the new materials are the result of combining the best alloy and technological characteristics of the standard nickel-based 


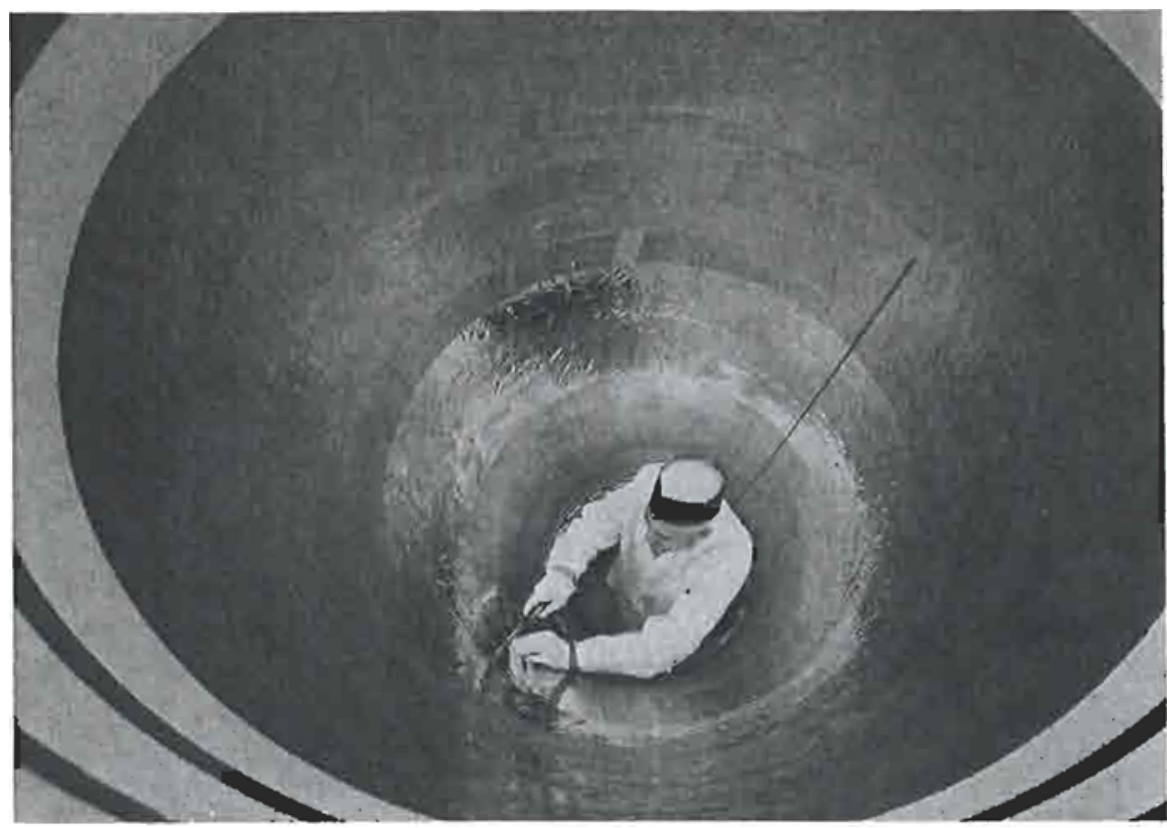

Fig. I Theinterior of thenozzle of theSpace Shuttle Main Engine is completely sheathed with gold alloy foil so that the cooling tubes can be brazed to the nozzle wall. Photograph by Rocketdyne Division, Rockwell International.

and high-gold or palladium-containing nickel filler metals. Important considerations of the alloy development programme were:

(1) To cost-optimize the use of precious or semi-precious metals

(2) To lower brazing temperatures and cycle times, thus using energy more economically

(3) To reduce hard phases in brazed joints.

The investigators systematically studied the dependence of melting behaviour and phase formation on alloy composition in the nickel-gold-chromium-boron-silicon system and a similar system using palladium instead of gold. Both precious metals form lowmelting eutectics with the metalloids silicon and boron, which had led previously to the development by Fairbanks(1) of the filler metal of composition: $20.5 \mathrm{gold} / 5.3 \mathrm{chromium} / 3.4$ silicon $/ 2.3 \mathrm{iron} / 2.3$ boron/66.2nickel (bal.) weight percent. Based on this work, nickelbased fillermetals with optimum melting behaviourand precious metal content were developed in the present, reported study.

'The compositions of the 'standard' alloys, and their brazing characteristics are given in Table I, together with the compositions of the alloys developed in this study.

Compared to the 'standard' materials, the melting range shown by the new compositions is, in general, reduced with decreasing gold or palladium content. In fact, the narrow melting range of alloy NiAu-2, indicates that it is near the eutectic point of the sixcomponent system. All other factors remaining equal a smaller melting range will adversely affect fluidity, that is the ability of the molten alloy toflow and fill a joint. Furthermore, the boron content of the alloys is increased with decreasing precious metal content, which tends to increase the erosive quality of the filler alloy, and, in addition, because of the high diffusivity of boron into most engineering alloys, can result in the reduction of their melting or softening temperatures and increase the extent of formation of brittle borides at the grain boundaries.

One important aspect of thestudy was the determination of the effect of joint spacing (that is fillermetal thickness) on the formation of brittle intermetallic compounds. By preparing brazing test specimens with a controlled wedge-shaped gap, evaluation of the 'Maximum Brazing Clearance' (MBC) could be made for different compositions and brazing conditions. The MBC is defined as the greatest clearance between components which does not permit the formation of hard particles.

The MBC's achieved by the various filler alloys after different brazing times are shown in Figure 2. For brazing cycle times of 60 minutes, the MBC's for all gold-containing alloys are seen to be substantially greater than those for other palladium-containing or non-precious nickel alloys. The significance of the high $\mathrm{MBC}$ values of the gold-containing fillers is that they permit broadening of the machining tolerances of components because of the better gapfilling capability of the gold alloys. For brazing cycle times of $60 \mathrm{~min}$ $\mathrm{MBC}$ values of between 24 and $77 \mu \mathrm{m}$ were obtained; after 120 minutes all of the alloys studied exhibited $M B C$ values close to or greater than $100 \mu \mathrm{m}$.

\section{Strength Testing}

Evaluation of the room-temperaturemechanical properties of the various brazing filler metals under test was carried out by utilizing standard lap-shear specimens of AISI 321 stainless steel. All specimens, brazed with overlap distance ranging between 0.5 and 
Table I

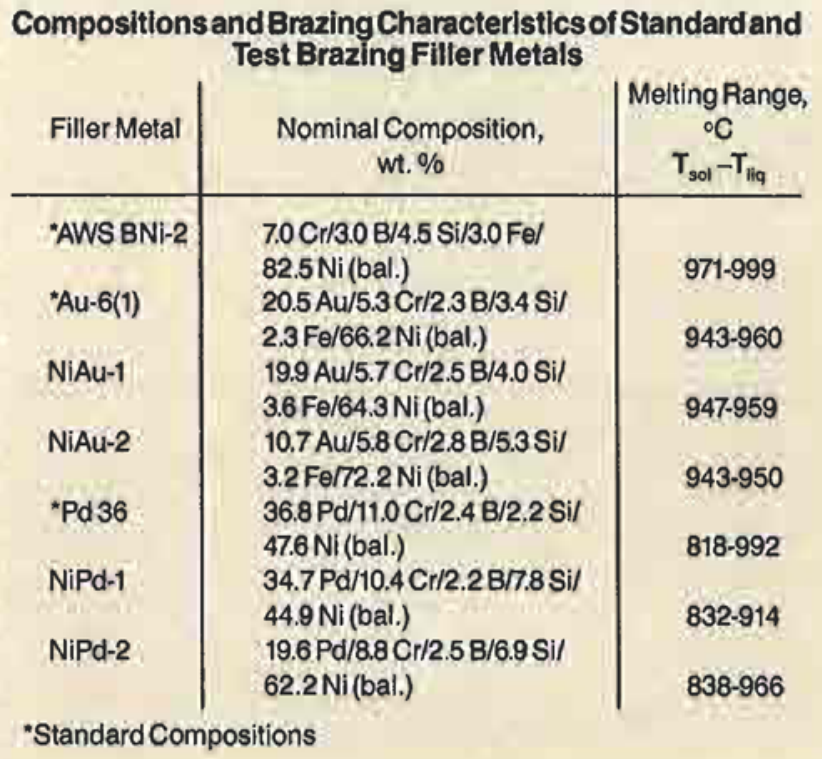

5 times the base metal thickness, were vacuum furnace-brazed for one hour at $1000^{\circ} \mathrm{C}$. The clearance (spacing) was $50 \mu \mathrm{m}$ in all cases. The relative tensile strengths of the brazed samples are shown in Figure 3.

With one exception, the results appear to indicate the existence of a curious ranking of the strengths of the four alloys in direct correlation with the nobility of the alloy, with regard to both the alloying metal (gold versuspalladium) and the fraction thereof. As is typical for all classes of brazing filler metals with a joint overlap equal to or greater than three times base metal thickness, failure occurred in the base metal, except in the case of NiPd-2, where the joint clearance $-50 \mu \mathrm{m}$ - was only slightly less than the MBC for the alloy. This can be compared to the NiPd-1 alloy for which the joint clearance was nearly twice the $\mathrm{MBC}$; this anomaly is unexplained.

\section{Reference}

1 N.P. Fairbanks, in 'Development of Low Gold Filler Metals', in 7 th Int. AWS Brazing Conf., St. Louis, Missouri, U.S.A., 1976; U.S. Pat. 3,853,548(1976)

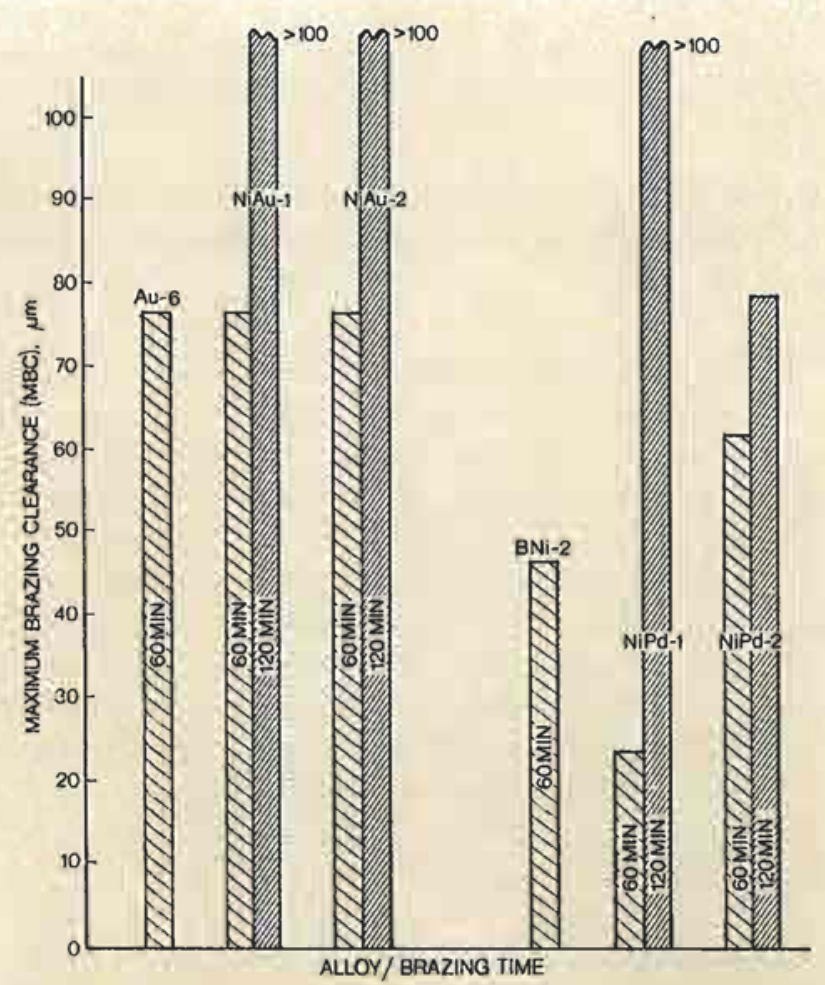

Fig. 2 Maximum Brazing Clearance for various alloys noted in Table I twhen brazed for different times. After Lugscheider and Pelster

Fig. 3 Relative tensile strengths of lap-shear specimens brazed with various filler metals described in Table I. After Lugscheider and Pelster

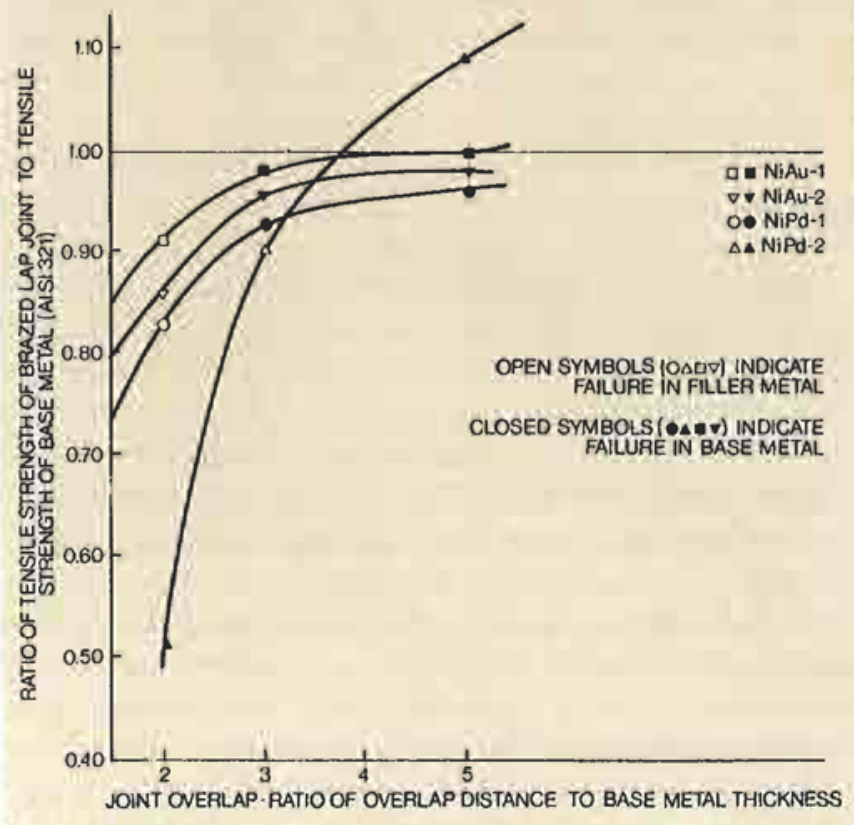

